\title{
ARTICLE
}

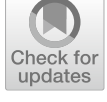

Cite as

Nano-Micro Lett.

(2021) 13:98

Received: 8 November 2020

Accepted: 8 December 2020

Published online: 30 March 2021

(C) The Author(s) 2021

\section{From Micropores to Ultra-micropores inside Hard Carbon: Toward Enhanced Capacity in Room-/ Low-Temperature Sodium-Ion Storage}

\author{
Jinlin Yang ${ }^{1,2,3}$, Xiaowei Wang ${ }^{2}$, Wenrui Dai ${ }^{2,3}$, Xu Lian $^{2}$, Xinhang Cui ${ }^{3,4}$, \\ Weichao Zhang ${ }^{5}$, Kexin Zhang ${ }^{6}$, Ming Lin ${ }^{7}$, Ruqiang Zou ${ }^{6}$, Kian Ping Loh ${ }^{2}$, \\ Quan-Hong Yang ${ }^{1,5}$, Wei Chen ${ }^{1,2,3,4} \bowtie$
}

\section{HIGHLIGHTS}

- Hard-carbon anode dominated with ultra-micropores $(<0.5 \mathrm{~nm})$ was synthesized for sodium-ion batteries via a molten diffusion-carbonization method.

- The ultra-micropores dominated carbon anode displays an enhanced capacity, which originates from the extra sodium-ion storage sites of the designed ultra-micropores.

- The thick electrode $\left(\sim 19 \mathrm{mg} \mathrm{cm}^{-2}\right)$ with a high areal capacity of $6.14 \mathrm{mAh} \mathrm{cm}^{-2}$ displays an ultrahigh cycling stability and an outstanding low-temperature performance.

ABSTRACT Pore structure of hard carbon has a fundamental influence on the electrochemical properties in sodium-ion batteries (SIBs). Ultra-micropores $(<0.5 \mathrm{~nm})$ of hard carbon can function as ionic sieves to reduce the diffusion of slovated $\mathrm{Na}^{+}$but allow the entrance of naked $\mathrm{Na}^{+}$into the pores, which can reduce the interficial contact between the electrolyte and the inner pores without sacrificing the fast diffusion kinetics. Herein, a molten diffusion-carbonization method is proposed to transform the micropores $(>1 \mathrm{~nm})$ inside carbon into ultra-micropores $(<0.5 \mathrm{~nm})$. Consequently, the designed carbon anode displays an enhanced capacity of $346 \mathrm{mAh} \mathrm{g}^{-1}$ at $30 \mathrm{~mA} \mathrm{~g}^{-1}$ with a high ICE value of $\sim 80.6 \%$ and most of the capacity $(\sim 90 \%)$ is below $1 \mathrm{~V}$. Moreover, the high-loading electrode $\left(\sim 19 \mathrm{mg} \mathrm{cm}^{-2}\right)$ exhibits a good temperature endurance

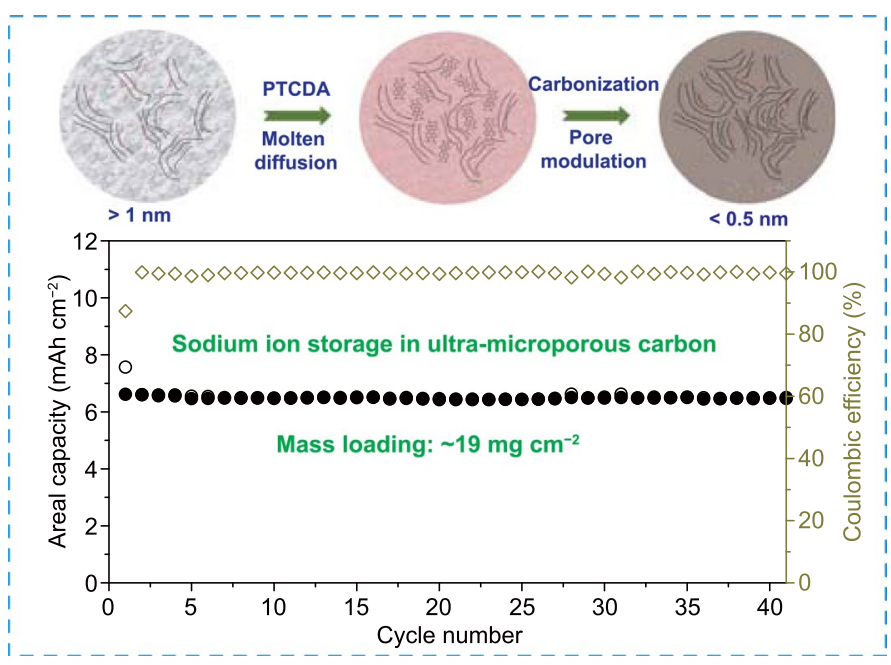
with a high areal capacity of $6.14 \mathrm{mAh} \mathrm{cm}^{-2}$ at $25{ }^{\circ} \mathrm{C}$ and $5.32 \mathrm{mAh} \mathrm{cm}^{-2}$ at $-20{ }^{\circ} \mathrm{C}$. Based on the in situ X-ray diffraction and ex situ solid-state nuclear magnetic resonance results, the designed ultra-micropores provide the extra $\mathrm{Na}^{+}$storage sites, which mainly contributes to the enhanced capacity. This proposed strategy shows a good potential for the development of high-performance SIBs.

KEYWORDS Carbon anode; Ultra-micropores; Extra sodium-ion storage sites; Low-voltage capacity; High areal capacity

Quan-Hong Yang, qhyangcn@tju.edu.cn; Wei Chen, phycw@nus.edu.sg

1 Joint School of National University of Singapore and Tianjin University, International Campus of Tianjin University, Binhai New City,

Fuzhou 350207, People's Republic of China

2 Department of Chemistry, National University of Singapore, 3 Science Drive 3, Singapore 117543, Singapore 


\section{Introduction}

Sodium-ion batteries (SIBs) have been considered as an important supplement to lithium-ion batteries (LIBs) due to its earth abundancy $[1,2]$. Intensive research efforts have been devoted to the development of electrolytes and cathode materials for SIBs [3-6]. High-performance anode materials, which play an equally important role in the further improvement of energy density in SIBs [7, 8], still need rapid development. However, the commercially available graphite anode in LIBs is not suitable for SIBs because of the positive formation energy of Na-graphite intercalation compounds (Na-GIC) [9]. Compared with alloy- and conversion-based anode materials with high plateau voltage and poor cycling stability [10-15], hard carbon has been considered as a promising candidate for the anode materials of SIBs due to its lower plateau voltage and acceptable capacity $\left(\sim 300 \mathrm{mAh} \mathrm{g}^{-1}\right)[16,17]$. Stevens and Dahn demonstrated the feasibility of hard carbon anode in SIBs and proposed a "card-house" model for $\mathrm{Na}^{+}$storage mechanism in glucose-derived hard carbon $[18,19]$, revealing the intercalation of $\mathrm{Na}^{+}$inside the stacked graphene layers (sloping region) and the pore-filling of $\mathrm{Na}^{+}$into the nanovoids (plateau region). The intercalation and insertion of $\mathrm{Na}^{+}$into the graphitic interlayers and nanovoids of hard carbon were also demonstrated by Komaba et al. [20]. Grey et al. and Gotoh et al. verified that the plateau capacity can be ascribed to the pore filling of $\mathrm{Na}^{+}$into the nanovoids from the ${ }^{23} \mathrm{Na}$ solid-state NMR results [21, 22]. However, Cao et al. [23] and Qiu et al. [24] elucidated that the plateau capacity originates from the intercalation/deintercalation of $\mathrm{Na}^{+}$into/ from the graphitic interlayer spacing larger than $0.37 \mathrm{~nm}$. Ding et al. [25], Lotfabad et al. [26], and Alvin et al. [27] also attributed the plateau capacity to the intercalation of $\mathrm{Na}^{+}$into the graphitic interlayers. Furthermore, Bommier et al. [28] revealed the linear relationship between sloping capacity and defect concentration and the coexistence of the intercalation and pore-filling process in the plateau region.
It has also been suggested that the heteroatom-doping can contribute to the plateau capacity through a systematic firstprinciples calculation study $[29,30]$. However, Zhang et al. [31] reported that there is no intercalation in the sloping and plateau region during the sodiation process via in situ X-ray diffraction (XRD) measurements for hard carbon.

Low-voltage capacity of anode can enable a higher energy density in full-cell batteries. Therefore, several approaches have been developed to increase the low-voltage capacity. Meng et al. [32], Li et al. [33], Lu et al. [34], Zhao et al. [35] , Li et al. [36, 37] used a pore-forming agent or adopted preoxidation/high-temperature carbonization to tune the closed pore structure of the hard carbon and hence to realize a large reversible plateau capacity. Choi et al. [38] obtained hard carbon fibers with a high plateau capacity by heating waste silk fabrics even at an ultrahigh temperature of $2000{ }^{\circ} \mathrm{C}$. Despite of the aforementioned advances in the synthesis of hard carbon with enhanced reversible plateau capacity, a high carbonization temperature (much higher than $1300{ }^{\circ} \mathrm{C}$ ) imposes a difficulty for practical applications. In addition, a poor rate capability always accompanies with the high plateau capacity. Therefore, it is essential to develop hard carbons with designed structures under a mild temperature, and to realize a large plateau capacity and satisfying rate capability.

Disordered porous carbon, such as biomass-derived carbon [39], and porous coordination polymer-derived carbon [40], can be readily synthesized under a mild temperature lower than $1000^{\circ} \mathrm{C}$. These porous carbon materials deliver improved diffusion kinetics and a satisfying rate capability in SIBs, originating from the existence of the well-developed porosity [41-43]. However, their discharge/charge profiles are dominated by sloping curves, due to the capacitive ion adsorption/desorption on the surface sites of the micropores, where the bare $\mathrm{Na}^{+}$and solvated $\mathrm{Na}^{+}$co-exist $[44,45]$. It is found that the existing electrolyte has a significant influence on the ionic interaction inside the pore [46]. If the electrolyte can be prevented to diffuse into the micropores, a different storage mechanism from the capacitive adsorption can be introduced. As previously reported, the

\footnotetext{
3 National University of Singapore (Suzhou) Research Institute, 377 Lin Quan Street, Suzhou Industrial Park, Suzhou 215123, Jiangsu, China

4 Department of Physics, National University of Singapore, 2 Science Drive 3, Singapore 117542, Singapore

5 Nanoyang Group, State Key Laboratory of Chemical Engineering, School of Chemical Engineering and Technology, Tianjin University, Tianjin 300350, People's Republic of China

6 Beijing Key Laboratory for Theory and Technology of Advanced Battery Materials, Department of Materials Science and Engineering, College of Engineering, Peking University, Beijing 100871, People's Republic of China

7 Institute of Materials Research and Engineering (IMRE), Agency of Science, Technology, and Research (A*STAR), 3 Research Link, Singapore 117602, Singapore
} 
aperture size of carbon materials displays an ionic-sieving effect on the solvated $\mathrm{Na}^{+}$and the pore size has a great influence on the electron distribution inside the pore [46-50]. Specifically, the desolvation will happen around the aperture when the aperture size is smaller than the solvated $\mathrm{Na}^{+}[47-49,51-53]$. In addition, according to the previous theoretical results, the $\mathrm{Na}^{+}$ concentration inside the pore increases with the decreasing pore inner diameter $[46,50]$. Moreover, the electrons tend to be spread out over all neighboring $\mathrm{Na}^{+}$instead of a single $\mathrm{Na}^{+}$ inside the pore with the decreasing pore inner diameter [46]. The tendency of $\mathrm{Na}^{+}$clustering inside the pores thereby becomes feasible. Given that the micropores $(>1 \mathrm{~nm})$ in porous carbon can be transformed to ultra-micropores with a smaller aperture size and pore inner diameter, pore-filling and clustering of bare $\mathrm{Na}^{+}$instead of slovated $\mathrm{Na}^{+}$can be introduced and the fast diffusion of $\mathrm{Na}^{+}$can still be ensured during the sodiation/desodiation process. Besides, the exclusion of solvent insides the pores can ensure more $\mathrm{Na}^{+}$storage sites, which is beneficial to enhance the capacity. Therefore, tuning the aperture size and pore inner diameter of porous carbon shows great potential to significantly improve the capacity without sacrificing the rate capability.

In this work, we developed an approach to effectively increase ultra-micropores inside the carbon materials through molten diffusion of aromatic hydrocarbons into the microporous carbon followed by further carbonization. The optimized carbon anode displays an enhanced capacity of 346 $\mathrm{mAh} \mathrm{g}^{-1}$ at $30 \mathrm{~mA} \mathrm{~g}^{-1}$ with most of capacity ( 90\%) below $1 \mathrm{~V}$, which is beneficial for the high working voltage of a practical full-cell battery. Moreover, the high-loading electrode $\left(\sim 19 \mathrm{mg} \mathrm{cm}^{-2}\right)$ also exhibits a high areal capacity of 6.14 $\mathrm{mAh} \mathrm{cm}{ }^{-2}$ at $25^{\circ} \mathrm{C}$ and $5.32 \mathrm{mAh} \mathrm{cm}^{-2}$ at $-20{ }^{\circ} \mathrm{C}$, revealing a good temperature endurance. Furthermore, the coin-type full battery enables a high capacity of $\sim 97.1 \mathrm{mAh} \mathrm{g}^{-1}$. The proposed molten diffusion-carbonization method is facile and energy-efficient to prepare high-performance carbon anode materials with great practical potential for SIBs.

\section{Experimental Section}

\subsection{Chemicals and Materials}

Activated carbon (AC, XFP06) and cubic structure of mesoporous carbon (CMK-8, XFP02) were purchased from Jiangsu XFNANO Materials Tech Co., Ltd. Perylene3,4,9,10-tetracarboxylic dianhydride (PTCDA) and potassium hydroxide $(\mathrm{KOH}, \mathrm{AR}$, pellets, $\geq 85 \%)$ were obtained from SIGMA-ALDRICH PTE LTD. All the chemicals used throughout this work were used as received without any further purification.

\subsection{Synthesis of GC}

The dried PTCDA was heated to $900{ }^{\circ} \mathrm{C}$ in argon at a rate of $5^{\circ} \mathrm{C} \min ^{-1}$ and then maintained for $5 \mathrm{~h}$. The furnace was then cooled to room temperature at a rate of $5^{\circ} \mathrm{C} \mathrm{min}^{-1}$. The obtained product was denoted as GC.

\subsection{Synthesis of $\mathrm{AC}+\mathrm{GC}$}

AC and GC powders with a mass ratio of 1:1 was mechanically mixed completely, which is denoted as AC + GC.

\subsection{Synthesis of AC1050}

The AC powder was heated to $1050{ }^{\circ} \mathrm{C}$ in argon at a rate of $5{ }^{\circ} \mathrm{C} \mathrm{min}{ }^{-1}$ and then maintained for $5 \mathrm{~h}$. The furnace was then cooled to room temperature at a rate of $5^{\circ} \mathrm{C} \mathrm{min}^{-1}$. The obtained product was denoted as AC1050.

\subsection{Synthesis of ACGCx}

The AC and PTCDA were vacuum-dried overnight at $110{ }^{\circ} \mathrm{C}$ before use. The dried AC and PTCDA were mechanically mixed. The mass ratio of the AC and PTCDA was calculated according to the pore volume of $\mathrm{AC}$ and the density of PTCDA (e.g., for $1.391 \mathrm{~cm}^{3} \mathrm{~g}^{-1}$ pore volume of AC, the mass ratio of the AC and PTCDA is about 1:2.36). The PTCDA was then encapsulated into the $\mathrm{AC}$ via molten diffusion-carbonization method in argon at $400^{\circ} \mathrm{C}$ for $3 \mathrm{~h}$, followed by further carbonization at a specific temperature for another $5 \mathrm{~h}$. Subsequently, the tube furnace was cooled down to room temperature at a rate of $5{ }^{\circ} \mathrm{C} \mathrm{min}^{-1}$. The obtained products carbonized at different temperature (i.e., $750,900,1050$, and $1200{ }^{\circ} \mathrm{C}$ ) were demoted as ACGC $x(x=750,900,1050,1200)$. 


\subsection{Synthesis of ACGC, CMK8GC, HCGC, and LCGC}

For hydrothermal reactions, $6.4 \mathrm{~g}$ sugar was dissolved into $40 \mathrm{~mL}$ water and heated at $180{ }^{\circ} \mathrm{C}$ for $8 \mathrm{~h}$. After drying, the obtained black powder (denoted as BP) was carbonized in Ar at $900{ }^{\circ} \mathrm{C}$ for $5 \mathrm{~h}$ at a rate of $3{ }^{\circ} \mathrm{C} \mathrm{min}{ }^{-1}$, which was denoted as LC (low-specific-surface-area arbon). For the synthesis of HC (high-specific-surface-area carbon), the dried BP was carbonized in $\mathrm{Ar}$ at $500{ }^{\circ} \mathrm{C}$ for $2 \mathrm{~h}$ at a rate of $5{ }^{\circ} \mathrm{C} \mathrm{min}{ }^{-1}$. Then the obtained product was physically mixed with $\mathrm{KOH}$ with a mass ratio of $1: 4$. The mixture was activated at $800{ }^{\circ} \mathrm{C}$ for $2 \mathrm{~h}$ at a rate of $5{ }^{\circ} \mathrm{C} \mathrm{min}^{-1}$. The synthesis of ACGC, CMK8GC HCGC, and LCGC are similar with that of ACGC1050.

\subsection{Characterizations}

Scanning electron microscopy (SEM, JSM6700F) and transmission electron microscopy (TEM, JEOL-2010) were adopted to characterize the electrode material. XRD patterns were collected from a Bruker D8 Advance X-ray diffractometer with $\mathrm{Cu} \mathrm{K} \alpha$ radiation of $1.5418 \AA$. The Raman spectra were collected on a Horiba Jobin Yvon Modular Raman Spectrometer at $514 \mathrm{~nm}$ (Green). The pore structures were investigated via $\mathrm{N}_{2}$ adsorption-desorption isotherms on a NOVA 2200e. The $\mathrm{CO}_{2}$ adsorption test was conducted on an Autosorb-iQ. ${ }^{23} \mathrm{Na}$ Magic Angle Spinning Nuclear Magnetic Resonance (MAS NMR) experiments was recorded on a Bruker Advance III 400 NMR spectrometer equipped with a superconducting magnet $(89 \mathrm{~mm}$ wide-bore $9.4 \mathrm{~T}$ ) and a HX probe $(1.3 \mathrm{~mm})$ at a Larmor frequency of 105.8 MHz. Single pulses were applied in acquiring ${ }^{23} \mathrm{Na}$ NMR data at a spinning speed of $80 \mathrm{kHz} .{ }^{23} \mathrm{Na}$ chemical shifts was referenced to $1 \mathrm{M} \mathrm{NaCl}$ solution. True density was measured via an AccuPyc II 1340 analyzer with Helium as analysis gas.

\subsection{Electrochemical Measurements}

CMCNa binder was first dissolved into DI water to form a uniform binder solution with a concentration of $12.5 \mathrm{mg} \mathrm{mL}^{-1}$. The vacuum-dried active material was subsequently added into the binder solution with a weight ratio of 90:10 for active material and binder. The slurry was stirred overnight and then pasted onto copper foil, followed by drying at $50{ }^{\circ} \mathrm{C}$ for $4 \mathrm{~h}$. Circular electrodes were obtained via a punch machine and then vacuum-dried at $120{ }^{\circ} \mathrm{C}$ for $12 \mathrm{~h}$. The mass loading of the electrode was $\sim 1.5-2.0 \mathrm{mg} \mathrm{cm}^{-2}$. The coin-type cells (2032) were assembled in an argon-filled glove box, with concentrations of moisture and oxygen below $0.2 \mathrm{ppm}$. Sodium metal was applied as the counter electrode. A Whatman GF/B glass fiber was adopted as the separator, and the electrolyte was a $1 \mathrm{M}$ sodium triflate (NaOTf) in diethylene glycol dimethyl ether (DEGDME). Galvanostatic discharge/charge results were collected from LANDCT2001 A galvanostats (Wuhan, China) in a range of $0.001-3.0 \mathrm{~V}$ (vs. $\mathrm{Na} / \mathrm{Na}^{+}$) at room temperature. $\mathrm{CV}$ cycling were conducted in a range of $0.001-3.0 \mathrm{~V}$ at a scan rate of $0.1 \mathrm{mV} \mathrm{s}^{-1}$ on an AUTOLAB electrochemical workstation. The full cells were assembled using a sodiated LCGC anode and PTCDA cathode or LCGC anode and a sodiated PTCDA cathode with a weight ratio of 1:2.54. The full cell was cycled in the range of $0.5-3.0 \mathrm{~V}$.

\section{Results and Discussion}

\subsection{Synthesis and Characterization of the Ultra-micropore Dominated Carbon}

A facile, cost-effective, and massive production process was developed to synthesize ultra-micropores $(<0.5 \mathrm{~nm})$ dominated hard carbon via a molten diffusion-carbonization method (Fig. 1a). Microporous carbon and perylenetetracarboxylic dianhydride (PTCDA) were first mechanically blended with a specific mass ratio and then annealed at $400^{\circ} \mathrm{C}$ in argon for $3 \mathrm{~h}$. Above the melting point $\left(\sim 350^{\circ} \mathrm{C}\right)$ of PTCDA, the molten PTCDA diffused into the microporous carbon and subsequently adsorbed on the inner surface of micropores [54]. During the further carbonization process, PTCDA inside the micropores was carbonized, while the residual PTCDA was evaporated and released with the argon flow. Commercial activated carbon (AC) was selected as a model host due to its developed porosity.

After the molten diffusion-carbonization process, the morphology of the micron-sized AC particles is maintained well without obvious residual of PTCDA-derived carbon, as revealed by SEM images in Figs. 1b, $c$ and S1. TEM images 
of the designed carbon, ACGC900 (the related abbreviations can be seen in the Sect. 2), reveal a disordered structure without obvious porosity, which is different from the microporous structure of AC (Figs. 1d and S2). The selected area electron diffraction (SAED) pattern of ACGC900 particle indicates a certain degree of graphitization with an obvious reflection ring corresponding to the (110) planes of graphitic structure, which can be attributed to the introduction of PTCDA-derived carbon inside the micropores (inset in Fig. 1d). Moreover, the Brunauer-Emmett-Teller (BET) specific surface area $\left(\mathrm{S}_{\mathrm{BET}}\right)$ is greatly reduced from $1429 \mathrm{~m}^{2} \mathrm{~g}^{-1}$ for $\mathrm{AC}$ to $48.4 \mathrm{~m}^{2} \mathrm{~g}^{-1}$ for the designed ACGC900. Compared with AC, the micropores with a size of $\sim 1.5 \mathrm{~nm}$ cannot be detected in ACGC900 (Fig. 1f), suggesting that most of the micropores are modulated to be ultra-micropores inaccessible by $\mathrm{N}_{2}$. Besides, the effect of the carbonization on the structure of $\mathrm{AC}$ is also explored (Fig. S3 and Table S2), indicating no obvious structure evolution. Notably, as shown in Figs. 1e and S12, there exists an obvious hysteresis between the $\mathrm{N}_{2}$ adsorption/desorption isotherms of ACGC $x$ ( $x=750,900,1050$, and 1200), indicating the existence of restricted pores or ultra-micropores

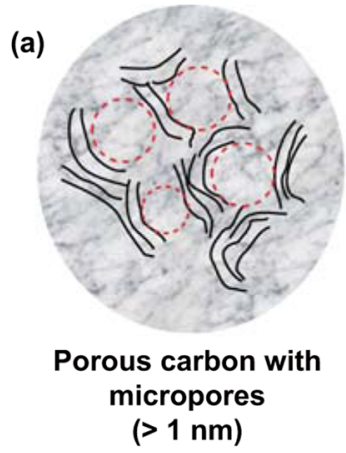

(b)
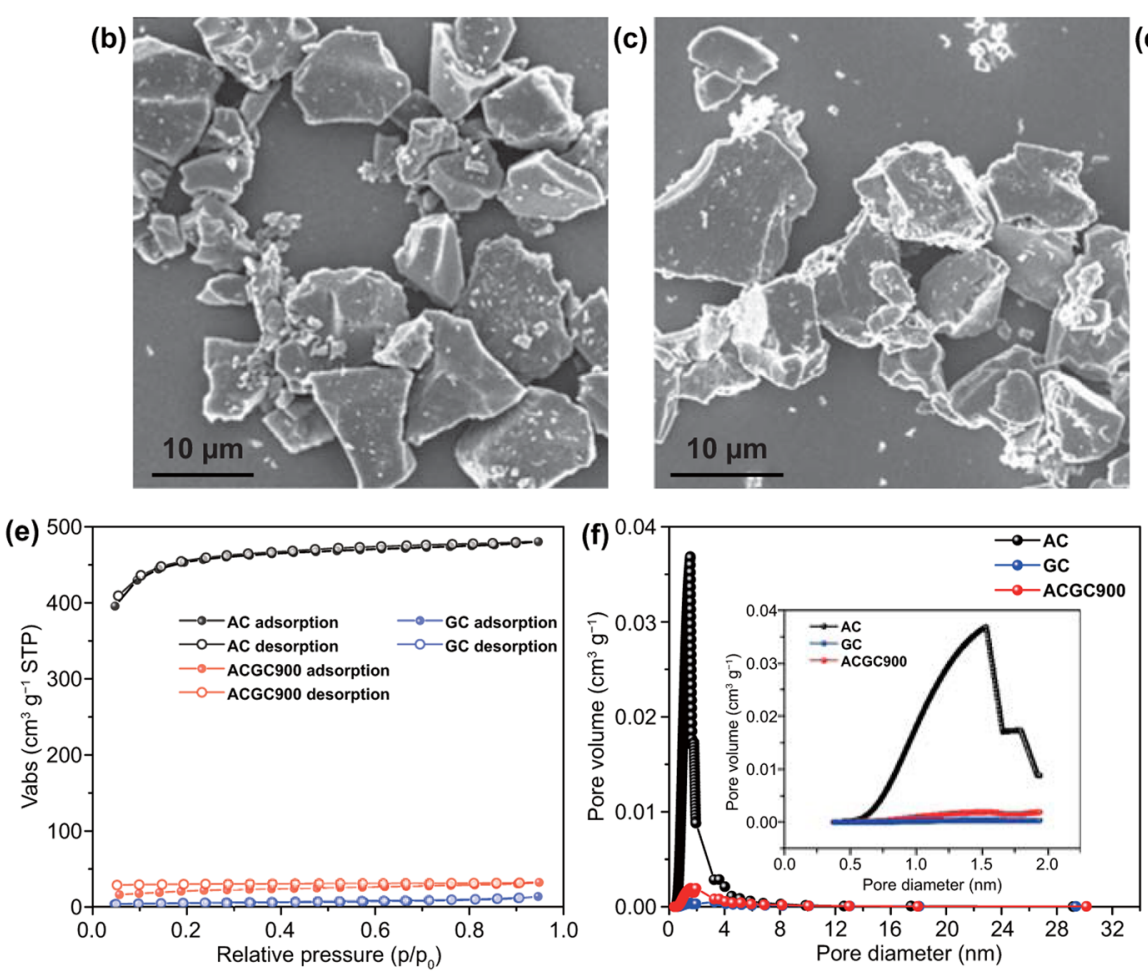
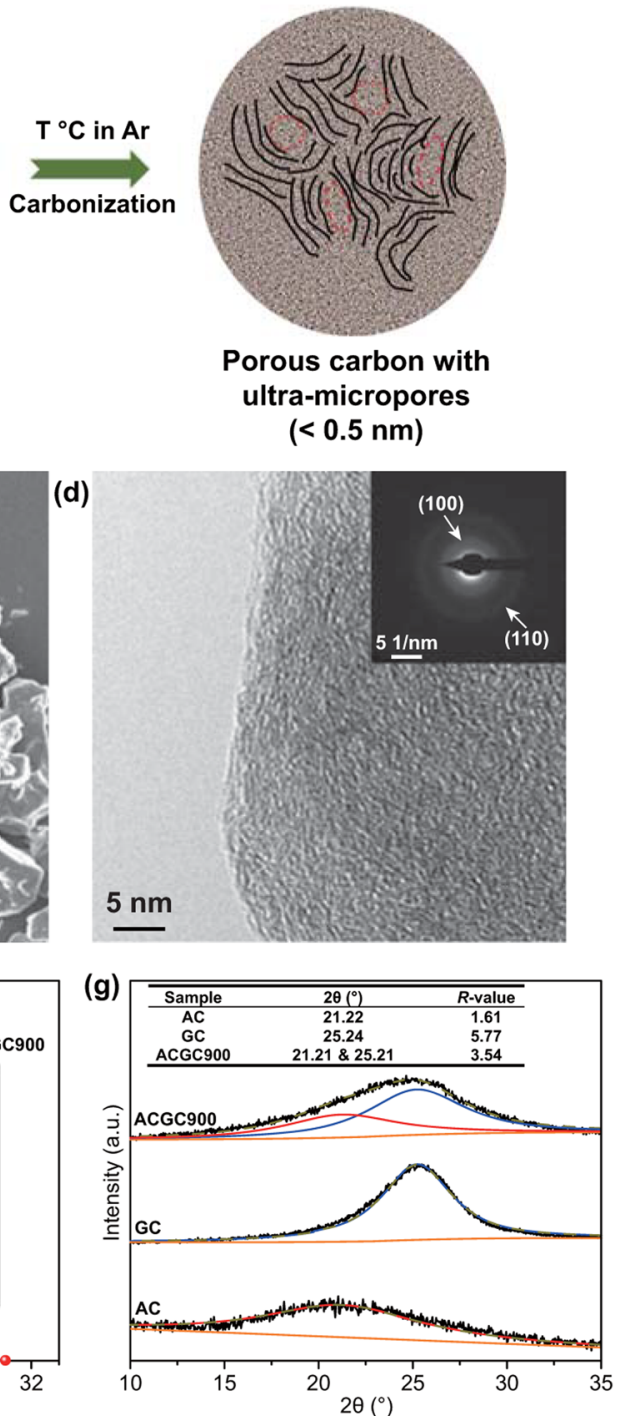

Fig. 1 Characterizations of the AC, GC and ACGC900. a Scheme of the molten diffusion-carbonization strategy (T represents the carbonization temperature). SEM image of b AC, and $\mathbf{c}$ ACGC900. d TEM image of ACGC900 and corresponding selected area electron diffraction (SAED) pattern (inset). e $\mathrm{N}_{2}$ adsorption/desorption isotherm, $\mathbf{f}$ pore size distribution from $\mathrm{N}_{2}$ adsorption/desorption measurement and $\mathbf{g}$ peak fitting of the (002) peaks in the XRD patterns 
[18]. Due to the smaller molecular size (3.3 $\AA$ for $\mathrm{CO}_{2}$ vs $3.64 \AA$ for $\mathrm{N}_{2}$ ) and the higher working temperature $(273 \mathrm{~K}$ for $\mathrm{CO}_{2}$ vs $77 \mathrm{~K}$ for $\mathrm{N}_{2}$ ), $\mathrm{CO}_{2}$ adsorption measurement is highly efficient to detect the existence of ultra-micropores $(<0.5 \mathrm{~nm})$ [55]. As displayed in Fig. S4 and Table S3, the $\mathrm{S}_{\mathrm{BET}}$ of ACGC900 calculated from $\mathrm{CO}_{2}$ adsorption measurement is $\sim 196.6 \mathrm{~m}^{2} \mathrm{~g}^{-1}$, much higher than that calculated from $\mathrm{N}_{2}$ adsorption/desorption. Moreover, the pore size of ACGC900 is mainly distributed at $0.3-0.5 \mathrm{~nm}$, along with a pore volume of $\sim 0.365 \mathrm{~cm}^{3} \mathrm{~g}^{-1}$. This reveals the existence of numerous ultra-micropores in ACGC900, which can reduce the interfacial contact between the inner surface of carbon and electrolyte and thus minimize side reactions.

The microstructure of the rationally designed carbon was further investigated via XRD measurements (Fig. 1g). Compared with that of AC, the (002) peak of ACGC900 becomes broader and shifts to a higher degree. By applying the profile-fitting method, the broad peak of ACGC900 can be divided into two parts [56]. Specifically, the fitted peak located at around $25.21^{\circ}$ and $21.21^{\circ}$ can match well with the (002) peak of the GC and AC, respectively (inset table in Fig. 1g). The coexistence of two different carbon phases further demonstrates the successful encapsulation, consistent with the SEM results (Fig. 1b, c). The $R$ value, an indicator of graphitization degree in carbon materials, is also calculated from XRD patterns (Fig. S5) [57]. As displayed in the inset table of Fig. 1g, the $R$ value of ACGC 900 is higher than that of $\mathrm{AC}$, indicating a higher graphitization degree for ACGC900, in good accordance with the Raman results (Fig. S6) [57]. The improved graphitization can ensure a good electroconductivity and hence enable a fast discharge/ charge capability.

\subsection{Electrochemical Performance in Sodium-Ion Batteries}

The electrochemical properties of AC, GC, and ACGC900 electrodes were evaluated by galvanostatic discharge/charge measurements. In Fig. 2a, the discharge/charge profiles of the $\mathrm{AC}$ and GC electrodes display all sloping curves in the voltage range of $0.001-3 \mathrm{~V}$, which mainly result from the capacitive storage of $\mathrm{Na}^{+}$on surface sites [49, 58]. For ACGC900 electrode, an apparent plateau appears at $\sim 0.1 \mathrm{~V}$ along with the sloping region between 0.1 and $1 \mathrm{~V}$. Accordingly, a couple of redox peaks at $\sim 0.1 \mathrm{~V}$ are also present in the cyclic voltammetry (CV) curves (Figs. 2b and S7). Moreover, the $\mathrm{Na}^{+}$storage behavior in the carbonized AC electrode keeps the same with that in the pristine AC electrode (Fig. S8), demonstrating the significant role of the molten-diffusion process. To further demonstrate the advantage of the designed structure, the mechanically mixed $\mathrm{AC}+\mathrm{GC}$ (mass ratio of $\mathrm{AC}$ and $\mathrm{GC}$ is 1:1) electrode was also fabricated. As shown in Fig. S9, nearly no redox peaks can be observed in the CV curves of the $\mathrm{AC}+\mathrm{GC}$ electrode, suggesting the significance of the molten diffusion process. As the sloping capacity of ACGC900 electrode is nearly equal to that of AC electrode, the increased capacity originating from the plateau region can be attributed to the extra storage sites from the ultramicropores. Furthermore, the cycling performance and rate capability of these three electrodes were compared in Figs. 2c and $\mathrm{S} 10$. When AC electrode was cycled at $50 \mathrm{~mA} \mathrm{~g}^{-1}$, sharp drop of capacity can be observed from the $10^{\text {th }}$ cycles onward and nearly no capacity can be obtained after 200 cycles. The rapid failure of AC electrode could be ascribed to the high accessible surface area and low electroconductivity, which can lead to increased solid electrolyte interface (SEI) layers $[59,60]$. While for ACGC900 electrode, 90\% initial capacity can be reserved after 200 cycles. The improved cycling stability could be ascribed to the structure after the encapsulation, including the reduced interfacial contact between the electrode and electrolyte and the increased degree of graphitization [61]. Besides, more than $100 \mathrm{mAh} \mathrm{g}^{-1}$ can be obtained for the ACGC900 electrode at $2000 \mathrm{~mA} \mathrm{~g}^{-1}$ while nearly no capacity for the AC electrode, further demonstrating the advantage of the designed structure after the molten diffusion-carbonization process.

To further explore the relationship between the microstructure and sodium-ion storage performance, ACGC $x(x=750,900,1050$, and 1200) samples were prepared under various carbonization temperatures. The morphology of ACGCx can be found in Fig. S11. Besides, $\mathrm{CO}_{2}$ and $\mathrm{N}_{2}$ adsorption/desorption measurements were conducted to explore the evolution of pore structure in ACGCx (Figs. S12 and S13), which are summarized in Tables S1 and $\mathrm{S} 3$. As shown in Tables $\mathrm{S} 1$ and $\mathrm{S} 3$, the $\mathrm{S}_{\mathrm{BET}}$ of ACGCX decreases with the increasing temperature. Moreover, the skeletal (true) density monotonically increases from 1.89 (ACGC750) to $2.14 \mathrm{~g} \mathrm{~cm}^{-3}$ (ACGC1200) as the temperature elevated, which is obtained from helium pycnometry measurement. These temperature-dependent properties suggest the formation of more ultra-micropores in ACGCx 

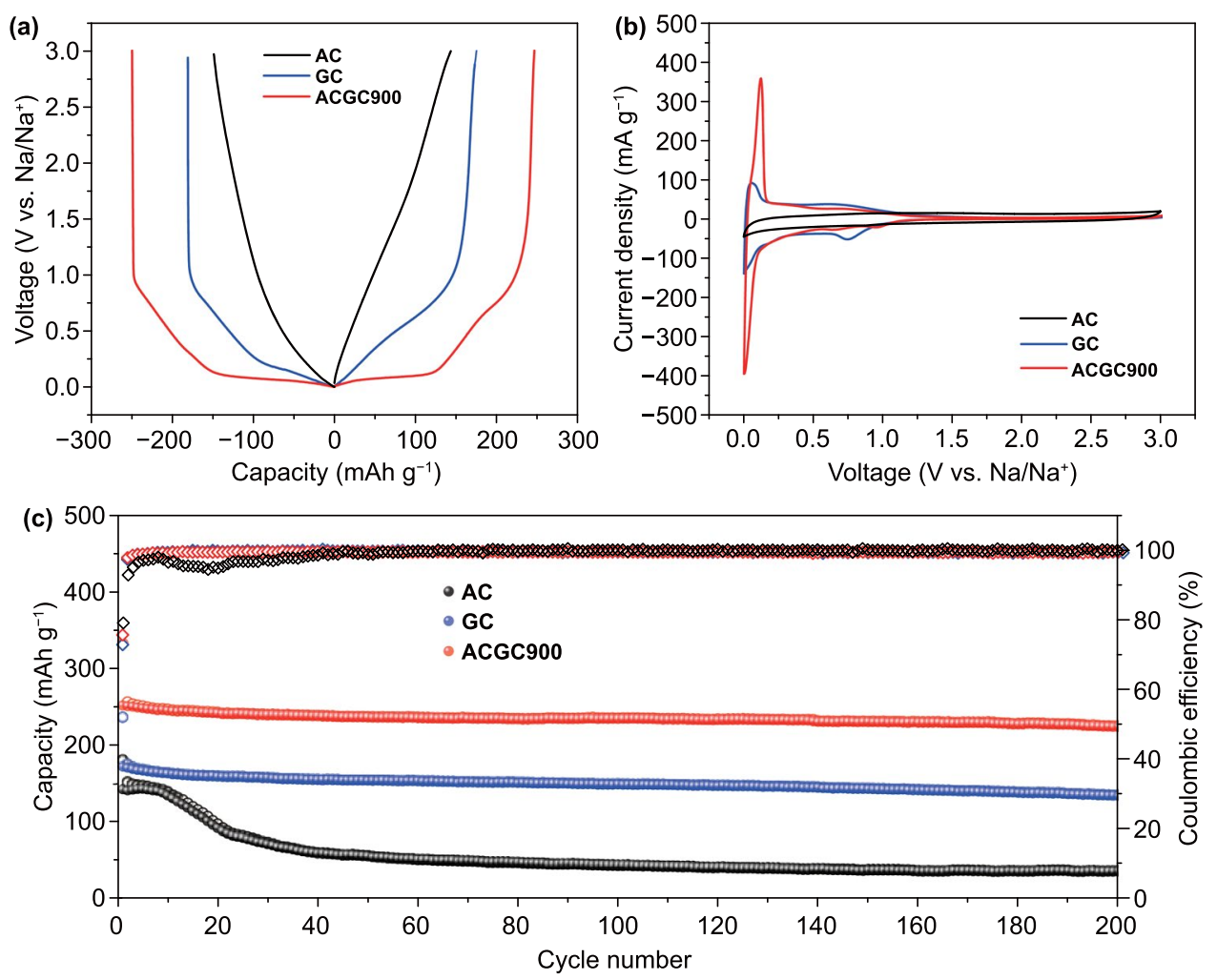

Fig. 2 Electrochemical performance of the AC, GC and ACGC900 electrode in SIBs: a Galvanostatic discharge/charge curves at $50 \mathrm{~mA} \mathrm{~g}^{-1}$. b

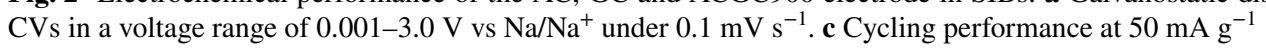

with increasing temperature. Figure 3a displays the discharge/charge curves of ACGCx electrodes at $50 \mathrm{~mA} \mathrm{~g}^{-1}$ with a voltage range of $0.001-3 \mathrm{~V}$. The increasing plateau capacity/sloping capacity ratio with the increased temperature indicates more $\mathrm{Na}^{+}$storage sites generating from the ultra-micropores, which is consistent with the results from helium pycnometry test and $\mathrm{CO}_{2}$ adsorption measurement. The interlayer spacing also evolves with the carbonization temperature. As shown in Fig. S14 and its inset table, the interlayer spacing decrease from 0.362 to $0.350 \mathrm{~nm}$ with the increasing carbonization temperature, while the plateau capacity does not decrease accordingly. This suggests that the intercalation is not the origin of the plateau capacity. On the contrast, the sloping capacity contribution decreases linearly with the increasing $\boldsymbol{R}$ value of ACGCx (Figs. 3b, S14-S16 and Table S4), where a lower $\boldsymbol{R}$ value suggests a lower degree of graphitization or more defect sites [28, 32]. The decreasing sloping capacity with increasing temperature could be attributed to the reduced defect sites, which can be further demonstrated by the relationship between the sloping capacity contribution and the $I_{\mathrm{D}} / I_{\mathrm{G}}$ ratio obtained from Raman spectra (Figs. S17, S18). Moreover, the initial coulombic efficiency (ICE) value increases linearly with the decreasing $\mathrm{S}_{\mathrm{BET}}$ from $\mathrm{N}_{2}$ adsorption/desorption measurement (Fig. S19 and Table S5), indicating reduced parasitic reactions toward electrolyte [61, 62].

The ACGC1050 electrode displays the highest plateau capacity and whole capacity among all ACGCx electrodes, along with the best rate performance and cycling stability (Fig. S20). Therefore, the optimized temperature is determined to be $1050{ }^{\circ} \mathrm{C}$. Furthermore, the relationship between the pore structure of the porous carbon host and the electrochemical performance was also studied at the optimized temperature (Figs. S21-S24 and Table S6). Specifically, LC (low $\mathrm{S}_{\mathrm{BET}}$ carbon, $224 \mathrm{~m}^{2} \mathrm{~g}^{-1}$ ) and $\mathrm{HC}$ (high $\mathrm{S}_{\mathrm{BET}}$ carbon, $2939 \mathrm{~m}^{2} \mathrm{~g}^{-1}$ ) were also selected as carbon host for comparison. After the molten diffusion-carbonization process, the obtained LCGC and HCGC materials suffer from huge reduction in specific surface area, which is in consistent with ACGC (Table S7). Besides, the skeletal (true) density of LCGC, ACGC, and HCGC are also compared in Table S7, suggesting various ultra-micropore volumes existing in these 

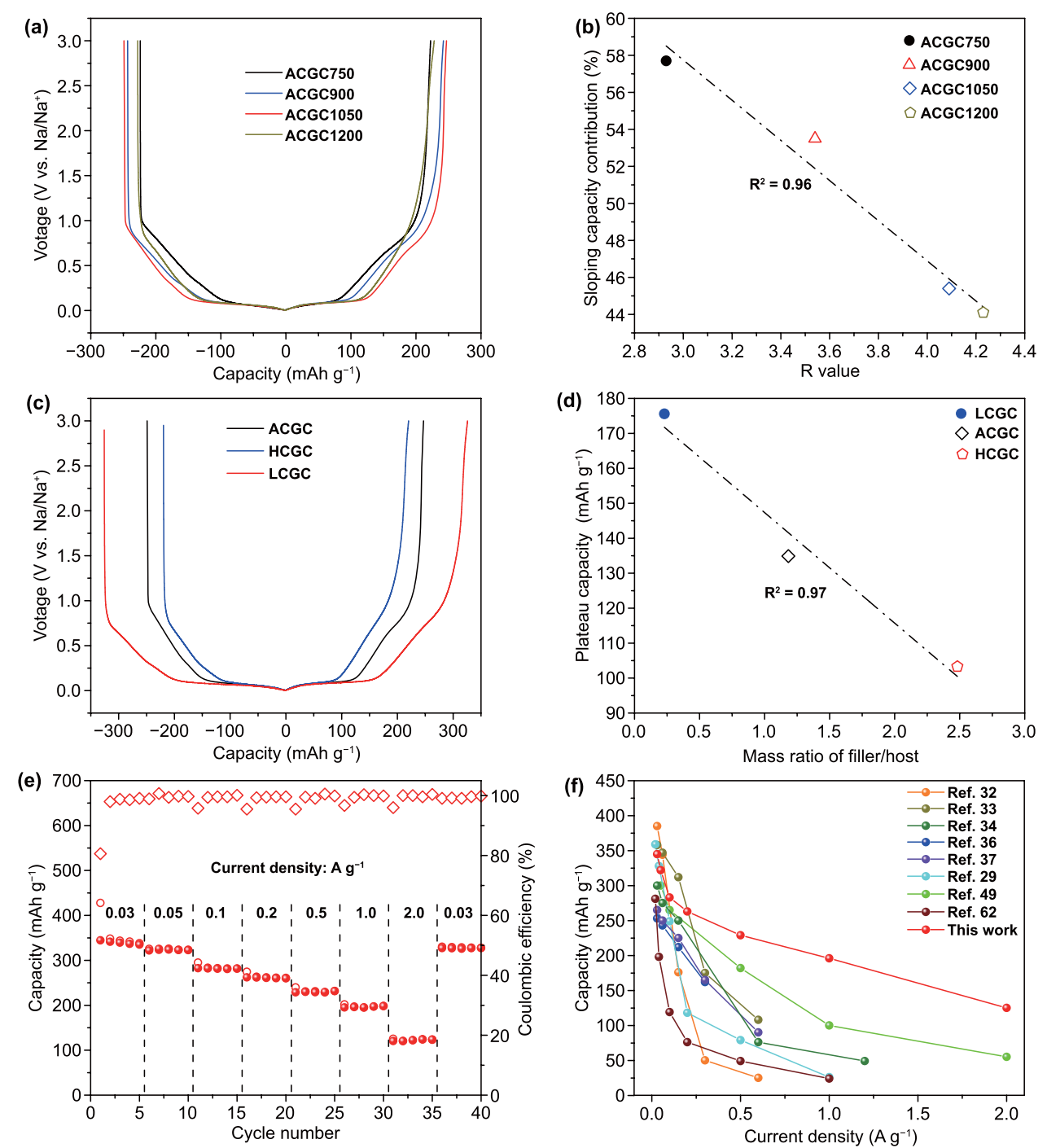

Fig. 3 Effects of carbonization temperature and pore volume on the electrochemical performance: a Galvanostatic discharge/charge curves of ACGCx at $50 \mathrm{~mA} \mathrm{~g}^{-1}$, and $\mathbf{b}$ the relationship between the sloping capacity contribution and the calculated $\boldsymbol{R}$ value from XRD. c Galvanostatic discharge/charge curves of ACGC, HCGC, LCGC electrodes at $50 \mathrm{~mA} \mathrm{~g}^{-1}$. d The relationship between the plateau capacity and the mass ratio of the filler/host. e rate performance and $\mathbf{f}$ the comparison of the rate performance of LCGC anode with that of hard carbon anodes recently reported in SIBs

carbon materials. As shown in Figs. 3c and S25, the LCGC electrode delivers the highest capacity among these carbon electrodes and a stable cycling performance. A quantitative relationship is built between the plateau capacity and the mass ratio of the filler/host, i.e., a lower filler/host ratio corresponding to more ultra-micropores can ensure a larger plateau capacity (Fig. 3d and Table S7). Therefore, porous carbon host with micropore-dominated structure and low $\mathrm{S}_{\mathrm{BET}}$ can enable more plateau capacity at the optimized temperature of $1050{ }^{\circ} \mathrm{C}$. Apart from a high reversible capacity of $346 \mathrm{mAh} \mathrm{g}^{-1}$ at $30 \mathrm{~mA} \mathrm{~g}^{-1}$, the LCGC electrode also demonstrates a satisfying rate capability. As shown in Fig. 3e, a high reversible capacity of $125 \mathrm{mAh} \mathrm{g}^{-1}$ can still be delivered at $2000 \mathrm{~mA} \mathrm{~g}^{-1}$, which reveals a superior performance compared to that of the previously reported hard carbon anode materials (Fig. 3f and Table S8) [29, 32-34, 36, 37, 49, 62].

\subsection{Sodium-Ion Storage Mechanism}

We propose that the introduction of ultra-micropores leads to the plateau capacity. To demonstrate the proposal, scan-ratedependent $\mathrm{CV}$ from 0.1 to $1.0 \mathrm{mV} \mathrm{s}^{-1}$ and the galvanostatic 
intermittent titration technique (GITT) measurements were further conducted (Figs. $4 \mathrm{a}-\mathrm{c}$ and S26-S28). During the discharge/charge process, both surface capacitive adsorption and diffusion-controlled process contribute to the sodiumion storage. The contribution ratio of the two mechanisms can be quantitatively determined by the power-law formula: $i=a v^{b}$. As displayed in Fig. 4b, the $b$-values of the highvoltage sloping region in ACGC electrode are $\sim 1.0$, corresponding to a fast adsorption/desorption of $\mathrm{Na}^{+}$at the surface-active sites [63, 64]. However, the $b$ values of the low-voltage plateau region in the ACGC electrode are 0.5 , suggesting a diffusion-controlled process [65]. Meanwhile, the profiles of the $\mathrm{Na}^{+}$diffusion coefficient $\left(D_{\mathrm{Na}}{ }^{+}\right)$as a function of potential reveal a U-turn point at $\sim 0.05 \mathrm{~V}$ during the discharge/charge process (Fig. 4c). The rapid drop of $\mathrm{D}_{\mathrm{Na}}{ }^{+}$ at $\sim 0.05 \mathrm{~V}$ could be ascribed to the large diffusion barrier for $\mathrm{Na}^{+}$insertion into the ultra-micropores, consistent with the low $b$-values of the low-voltage plateau region (Fig. 4b). The reverse increment of $\mathrm{D}_{\mathrm{Na}}{ }^{+}$near the cutoff voltage corresponds to the adsorption and clustering of the $\mathrm{Na}^{+}$inside the ultra-micropores. Therefore, the adsorption of $\mathrm{Na}^{+}$on the surface sites is a capacitive behavior, whereas the insertion of $\mathrm{Na}^{+}$into the ultra-micropores is a diffusion process.

In situ XRD measurement is an effective and real-time technique to detect the possible variation of interlayer spacing during the discharge/charge process. Hence, the in situ XRD pattern of the second discharge/charge cycle at $0.15 \mathrm{~mA} \mathrm{~cm}{ }^{-2}$ was collected for analysis. As shown in Fig. 4d, the band located at $25.6^{\circ}$ represents the (002) peak, suggesting a d-spacing of $\sim 3.5 \AA$. If intercalation exists, (002) peak detected from XRD pattern will experience a peak shifting during the discharge/charge process [66]. From Fig. 4d, e, no peak shift of the (002) peak or new peak can be observed during the whole process, suggesting no intercalation/deintercalation into/from the graphitic interlayers in both sloping region and plateau region. Raman spectra of the carbon electrode at various states were further collected to reveal any possible peak shift or new peaks during the sodiation/desodiation process. As shown in Fig. S29, the D-band $\left(1340 \mathrm{~cm}^{-1}\right)$ and G-band $\left(1580 \mathrm{~cm}^{-1}\right)$ keep the same peak location and no new peaks appear during the sodiation/desodiation process, suggesting no intercalation of $\mathrm{Na}^{+}$
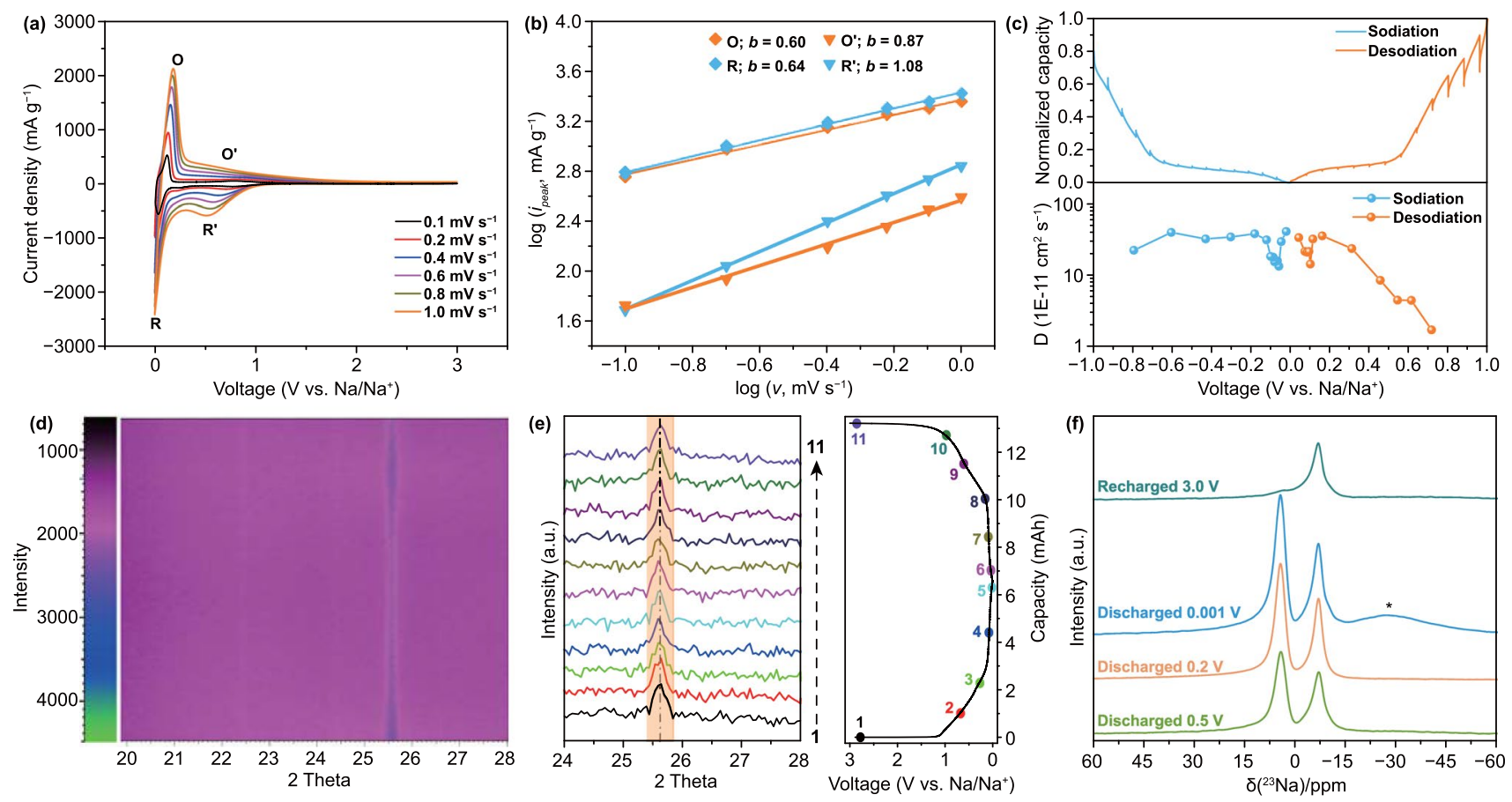

Fig. 4 Analysis of sodium-ion storage mechanism: a CV curves under various scan rates from 0.1 to $1.0 \mathrm{mV} \mathrm{s}^{-1}$, b the corresponding linear fitting of the plots between $\log (i)$ and $\log (v)$ and $\mathbf{c} D_{\mathrm{Na}}{ }^{+}$values calculated from GITT measurement during discharge/charge process. d, e The in situ XRD mapping with the capacity-potential curve under voltage windows of $0.001-3 \mathrm{~V}$. f The ex situ solid-state NMR spectra of ${ }^{23} \mathrm{Na}$ at different potentials 
into/from graphitic interlayers [33]. Along with the relationship between the sloping capacity and $\boldsymbol{R}$ value or $I_{\mathrm{D}} / I_{\mathrm{G}}$ ratio (Figs. 3b and S18), in situ XRD results further corroborate that the sloping capacity results from the adsorption/desorption of $\mathrm{Na}^{+}$to/from the surface sites, which is also in accordance with the high $b$-values of the sloping region.

To further explore the sodium-ion storage mechanism in the plateau region, ex situ ${ }^{23} \mathrm{Na}$ MAS NMR measurements were conducted. As shown in Figs. $4 \mathrm{f}$ and S30, two resonances at -6.87 and $4.44 \mathrm{ppm}$ can be observed in the spectra obtained from the electrode discharged to 0.5 and $0.2 \mathrm{~V}$. Note that there is no washing process for the electrode, the peak at $-6.87 \mathrm{ppm}$ can be ascribed to the sodium salt in the electrolyte. Along with discharging, the appearance of the peak at $4.44 \mathrm{ppm}$ indicates the adsorption of $\mathrm{Na}^{+}$on the surface sites [21]. When the electrode was fully discharged to $0.001 \mathrm{~V}$, a broad peak located between -20 and -30 ppm appears, indicating the existence of $\mathrm{Na}^{+}$with a more restricted mobility, e.g., in ultra-micropores [67]. When the electrode is recharged to $3 \mathrm{~V}$, only the peak at $-6.87 \mathrm{ppm}$ retains and other peaks disappear accordingly, suggesting the reversible storage of $\mathrm{Na}^{+}$on the surface and inside the ultra-micropores. Therefore, it is indeed the porefilling of $\mathrm{Na}^{+}$into the ultra-micropores that contribute to the
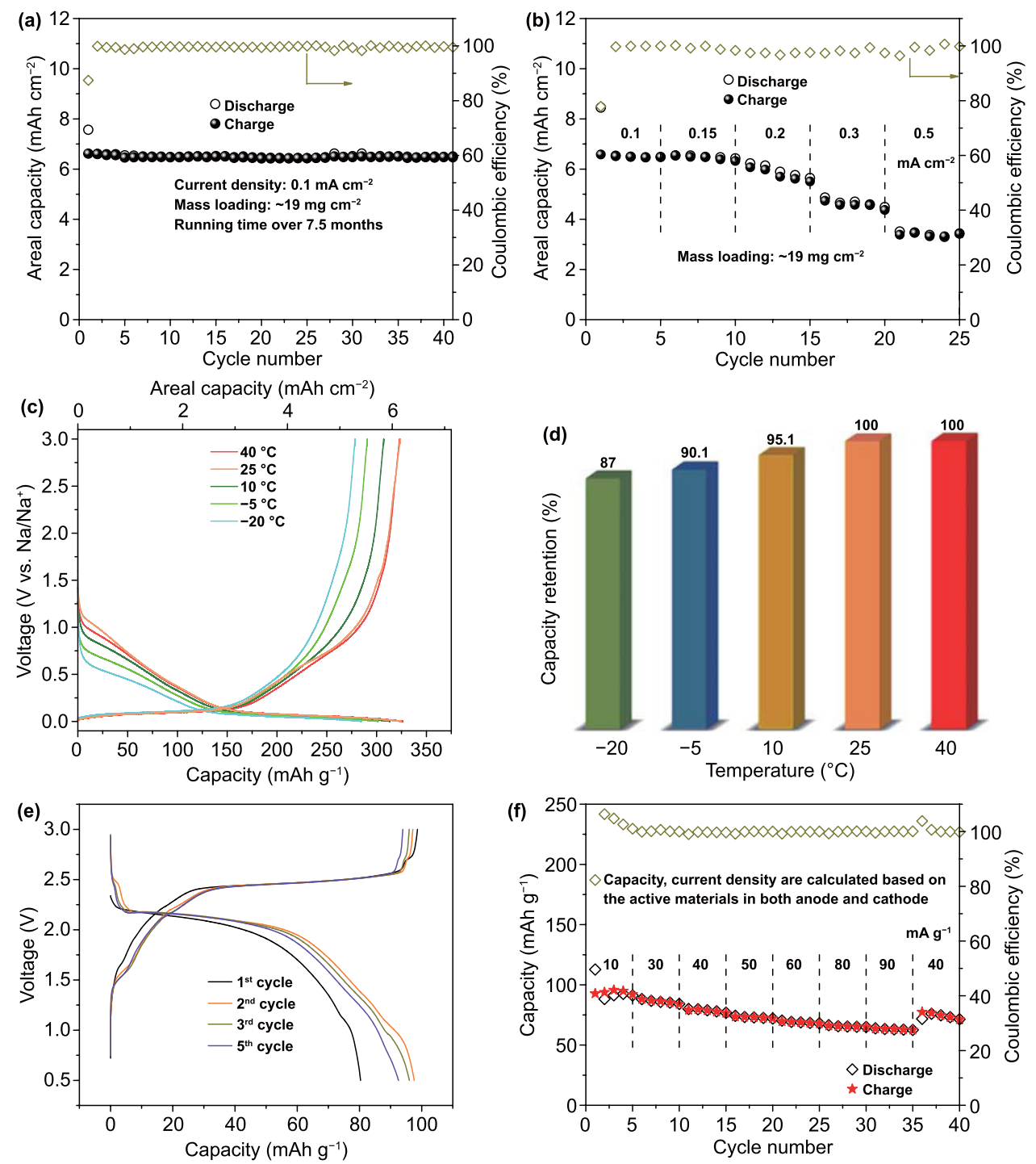

Fig. 5 Thick electrode and full-cell test. a Cycling performance, and $\mathbf{b}$ rate capability of the thick electrode with a mass loading of $\sim 19 \mathrm{mg} \mathrm{cm}$ ${ }^{-2}$. c galvanostatic discharge/charge curves at $0.2 \mathrm{~mA} \mathrm{~cm}{ }^{-2}$ in the temperature range from -20 to $40{ }^{\circ} \mathrm{C}$ and $\mathbf{d}$ the capacity retentions of thick electrode. e Galvanostatic discharge/charge curves at $10 \mathrm{~mA} \mathrm{~g}^{-1}$ and $\mathbf{f}$ rate capability of full cell in the voltage range of $0.5-3.0 \mathrm{~V}$ 
low-voltage plateau at $\sim 0.1 \mathrm{~V}$ [46]. Figure S31 schematically illustrates the aforementioned process in a sodiation process.

\subsection{Electrochemical Performance of Thick Electrodes and Full-cell Batteries}

For the practical applications, excellent sodium-ion storage performance under room-/low-temperature in thick electrode is crucial. Hence, a thick electrode of LCGC with a mass loading of $\sim 19 \mathrm{mg} \mathrm{cm}^{-2}$ was further fabricated. As shown in Fig. 5a, a high areal capacity of $6.14 \mathrm{mAh} \mathrm{cm}^{-2}$ can be achieved at $0.1 \mathrm{~mA} \mathrm{~cm}{ }^{-2}$. After 41 cycles $(\sim 7.5$ months cycling), nearly no capacity degradation can be observed, indicating an excellent cycling stability of this electrode even with a high mass loading. Compared with the high reversible capacity at a small current density $\left(0.1 \mathrm{~mA} \mathrm{~cm}^{-2}\right), \sim 53.1 \%$ of capacity $\left(3.26 \mathrm{mAh} \mathrm{cm}^{-2}\right)$ can still be maintained at a much higher current density $\left(0.5 \mathrm{~mA} \mathrm{~cm}^{-2}\right)$, indicating the superior rate capability of the fabricated thick electrode (Figs. $5 \mathrm{~b}$ and S32). As shown in Fig. 5c, the low-temperature performance of the thick LCGC electrode was further explored from -20 to $40{ }^{\circ} \mathrm{C}$. Specifically, the capacity retentions of the thick electrode are around 87, 90, 95, 100, and 100\% compared to the capacity obtained at $25^{\circ} \mathrm{C}$, respectively (Fig. $5 \mathrm{~d}$ ). Moreover, similar diffusion kinetics of $\mathrm{Na}^{+}$inside the thick electrode at various temperatures can be observed from the potential-dependant $\mathrm{D}_{\mathrm{Na}}{ }^{+}$profiles in Fig. S33, suggesting a satisfying low-temperature performance. Furthermore, the electrochemical performance was evaluated for a coin-type full battery. The LCGC anode and a sodiated organic cathode (PTCDA) were assembled into the full battery with a $\mathrm{N} / \mathrm{P}$ ratio (the areal capacity ratio of negative to positive electrode) of 1.15:1. Figure 5e displays the initial five discharge/ charge cycles of the full cell at $10 \mathrm{~mA} \mathrm{~g}^{-1}$ within a range of 0.5-3.0 V. A high reversible capacity of $\sim 97.1 \mathrm{mAh} \mathrm{g}^{-1}$ can be obtained. It is worth noting that the current density and the capacity are calculated from the total mass of the active materials. The rate capability of the full-cell battery was also evaluated via assembling a sodiated LCGC anode with the PTCDA cathode. When the current density is increased to $90 \mathrm{~mA} \mathrm{~g}^{-1}$, a reversible capacity of $63.6 \mathrm{mAh} \mathrm{g}^{-1}$ can be reserved with a capacity retention ratio of $67.7 \%$ (Fig. 5f), indicating an excellent rate capability of the full-cell battery.

\section{Conclusions}

In summary, we have developed a molten diffusion-carbonization strategy to block the micropores of porous carbon and transform them into ultra-micropores $(0.3-0.5 \mathrm{~nm})$. The ultra-micropores can only be accessible to the bare $\mathrm{Na}^{+}$without electrolytes, which can effectively minimize the decomposition of electrolytes and then induce a high ICE value of $\sim 80.6 \%$. The optimized anode exhibits a good electrochemical performance, i.e., high capacity, superior cycling stability, and satisfying rate performance. With the help of a series of scan-rate-dependent CV, GITT, in situ XRD, and ex situ solid-state NMR measurements, it is well demonstrated that the designed ultra-micropores provide the extra sodium-ion storage sites, which mainly contributes to the enhanced capacity. It is noteworthy that the thick electrode with a high areal capacity of $6.14 \mathrm{mAh} \mathrm{cm}^{-2}$ displays an ultrahigh cycling stability with a running time over 7.5 months, a satisfying rate capability and an outstanding low-temperature performance. Moreover, the coin-type full battery based on the PTCDA cathode and the sodiated anode possesses a high reversible capacity and superior rate performance. These findings suggest a promising strategy to design practical carbon anode materials for SIBs with high energy density, high rate performance and excellent lowtemperature performance.

Acknowledgements The authors acknowledge the financial support from Singapore MOE Tier II grant R143-000-A29-112 and the National Research Foundation under the Grant of NRF2017NRF-NSFC001-007.

Author contributions W. Chen and Q-H. Yang conceived the concept and directed the research. J. L. Yang designed the experiments, analyzed electrochemical data and wrote the manuscript. X. W. Wang carried out the in situ XRD characterization and gave advice on the fabrication of full-cell batteries and thick electrodes. W. R. Dai gave advice on the solid-state NMR characterization. K. $\mathrm{X}$. Zhang conducted the $\mathrm{CO}_{2}$ adsorption characterization. M. Lin conducted the TEM characterization. W. C. Zhang provided help on the synthesis of part of materials. W. Chen and Q-H. Yang supervised the overall study. All the authors discussed the manuscript and provided comments.

Open Access This article is licensed under a Creative Commons Attribution 4.0 International License, which permits use, sharing, adaptation, distribution and reproduction in any medium or format, as long as you give appropriate credit to the original author(s) and 
the source, provide a link to the Creative Commons licence, and indicate if changes were made. The images or other third party material in this article are included in the article's Creative Commons licence, unless indicated otherwise in a credit line to the material. If material is not included in the article's Creative Commons licence and your intended use is not permitted by statutory regulation or exceeds the permitted use, you will need to obtain permission directly from the copyright holder. To view a copy of this licence, visit http://creativecommons.org/licenses/by/4.0/.

Supplementary Information The online version of this article (https://doi.org/10.1007/s40820-020-00587-y) contains supplementary material, which is available to authorized users.

\section{References}

1. H. Hou, X. Qiu, W. Wei, Y. Zhang, X. Ji, Carbon anode materials for advanced sodium-ion batteries. Adv. Energy Mater. 7(24), 1602898 (2017). https://doi.org/10.1002/aenm.201602898

2. X. Wu, Y. Chen, Z. Xing, C.W.K. Lam, S.-S. Pang et al., Advanced carbon-based anodes for potassium-ion batteries. Adv. Energy Mater. 9(21), 1900343 (2019). https://doi.org/ 10.1002/aenm.201900343

3. Y. Shao, G. Zhong, Y. Lu, L. Liu, C. Zhao et al., A novel nasicon-based glass-ceramic composite electrolyte with enhanced Na-ion conductivity. Energy Storage Mater. 23, 514-521 (2019). https://doi.org/10.1016/j.ensm.2019.04.009

4. C. Zhao, F. Ding, Y. Lu, L. Chen, Y.S. Hu, High-entropy layered oxide cathodes for sodium-ion batteries. Angew. Chem. Int. Ed. 59(1), 264-269 (2020). https://doi.org/10.1002/anie. 201912171

5. J. Zhang, D.-W. Wang, W. Lv, L. Qin, S. Niu et al., Ethers illume sodium-based battery chemistry: Uniqueness, surprise, and challenges. Adv. Energy Mater. 8(26), 1801361 (2018). https://doi.org/10.1002/aenm.201801361

6. J. Zhang, D.-W. Wang, W. Lv, S. Zhang, Q. Liang et al., Achieving superb sodium storage performance on carbon anodes through an ether-derived solid electrolyte interphase. Energy Environ. Sci. 10(1), 370-376 (2017). https://doi.org/ 10.1039/C6EE03367A

7. Y. Lu, X. Rong, Y.-S. Hu, L. Chen, H. Li, Research and development of advanced battery materials in china. Energy Storage Mater. 23, 144-153 (2019). https://doi.org/10.1016/j.ensm. 2019.05.019

8. C. Zeng, F. Xie, X. Yang, M. Jaroniec, L. Zhang et al., Ultrathin titanate nanosheets/graphene films derived from confined transformation for excellent $\mathrm{Na} / \mathrm{K}$ ion storage. Angew. Chem. Int. Ed. 57(28), 8540-8544 (2018). https://doi.org/10. 1002/anie.201803511

9. Y. Liu, B.V. Merinov, W.A. Goddard, Origin of low sodium capacity in graphite and generally weak substrate binding of $\mathrm{Na}$ and $\mathrm{Mg}$ among alkali and alkaline earth metals. Proc. Natl. Acad. Sci. USA 113(14), 3735-3739 (2016). https://doi.org/ $10.1073 /$ pnas. 1602473113
10. H. Zhang, I. Hasa, S. Passerini, Beyond insertion for na-ion batteries: Nanostructured alloying and conversion anode materials. Adv. Energy Mater. 8(17), 1702582 (2018). https://doi. org/10.1002/aenm.201702582

11. F. Xie, L. Zhang, Q. Gu, D. Chao, M. Jaroniec et al., Multishell hollow structured $\mathrm{Sb}_{2} \mathrm{~S}_{3}$ for sodium-ion batteries with enhanced energy density. Nano Energy 60, 591-599 (2019). https://doi.org/10.1016/j.nanoen.2019.04.008

12. F. Xie, L. Zhang, C. Ye, M. Jaroniec, S.Z. Qiao, The application of hollow structured anodes for sodium-ion batteries: from simple to complex systems. Adv. Mater. 31(38), e1800492 (2019). https://doi.org/10.1002/adma.201800492

13. B. Chen, Y. Meng, F. Xie, F. He, C. He et al., 1D sub-nanotubes with anatase/bronze $\mathrm{TiO}_{2}$ nanocrystal wall for highrate and long-life sodium-ion batteries. Adv. Mater. 30(46), e1804116 (2018). https://doi.org/10.1002/adma.201804116

14. Y. Xiao, X. Zhao, X. Wang, D. Su, S. Bai et al., A nanosheet array of $\mathrm{Cu}_{2} \mathrm{Se}$ intercalation compound with expanded interlayer space for sodium ion storage. Adv. Energy Mater. 10(25), 2000666 (2020). https://doi.org/10.1002/aenm.202000666

15. Y. Xiao, D. Su, X. Wang, S. Wu, L. Zhou et al., CuS microspheres with tunable interlayer space and micropore as a highrate and long-life anode for sodium-ion batteries. Adv. Energy Mater. 8(22), 1800930 (2018). https://doi.org/10.1002/aenm. 201800930

16. D. Saurel, B. Orayech, B. Xiao, D. Carriazo, X. Li et al., From charge storage mechanism to performance: a roadmap toward high specific energy sodium-ion batteries through carbon anode optimization. Adv. Energy Mater. 8(17), 1703268 (2018). https://doi.org/10.1002/aenm.201703268

17. D.A. Stevens, J.R. Dahn, High capacity anode materials for rechargeable sodium-ion batteries. J. Electrochem. Soc. 147(4), 1271-1273 (2000). https://doi.org/10.1149/1.1393348

18. D.A. Stevens, J.R. Dahn, The mechanisms of lithium and sodium insertion in carbon materials. J. Electrochem. Soc. 148(8), A803-A811 (2001). https://doi.org/10.1149/1.1379565

19. D.A. Stevens, J.R. Dahn, An in situ small-angle X-ray scattering study of sodium insertion into a nanoporous carbon anode material within an operating electrochemical cell. J. Electrochem. Soc. 147(12), 4428-4431 (2000). https://doi.org/ 10.1149/1.1394081

20. S. Komaba, W. Murata, T. Ishikawa, N. Yabuuchi, T. Ozeki et al., Electrochemical $\mathrm{Na}$ insertion and solid electrolyte interphase for hard-carbon electrodes and application to Naion batteries. Adv. Funct. Mater. 21(20), 3859-3867 (2011). https://doi.org/10.1002/adfm.201100854

21. K. Gotoh, T. Ishikawa, S. Shimadzu, N. Yabuuchi, S. Komaba et al., NMR study for electrochemically inserted $\mathrm{Na}$ in hard carbon electrode of sodium ion battery. J. Power Sources 225, 137-140 (2013). https://doi.org/10.1016/j.jpowsour.2012.10. 025

22. J.M. Stratford, P.K. Allan, O. Pecher, P.A. Chater, C.P. Grey, Mechanistic insights into sodium storage in hard carbon anodes using local structure probes. Chem. Commun. 52(84), 12430-12433 (2016). https://doi.org/10.1039/C6CC06990H 
23. Y. Cao, L. Xiao, M.L. Sushko, W. Wang, B. Schwenzer et al., Sodium ion insertion in hollow carbon nanowires for battery applications. Nano Lett. 12(7), 3783-3787 (2012). https://doi. org/10.1021/nl3016957

24. S. Qiu, L. Xiao, M.L. Sushko, K.S. Han, Y. Shao et al., Manipulating adsorption-insertion mechanisms in nanostructured carbon materials for high-efficiency sodium ion storage. Adv. Energy Mater. 7(17), 1700403 (2017). https://doi.org/10.1002/ aenm.201700403

25. J. Ding, H. Wang, Z. Li, A. Kohandehghan, K. Cui et al., Carbon nanosheet frameworks derived from peat moss as high performance sodium ion battery anodes. ACS Nano 7(12), 11004-11015 (2013). https://doi.org/10.1021/nn404640c

26. E.M. Lotfabad, J. Ding, K. Cui, A. Kohandehghan, W.P. Kalisvaart et al., High-density sodium and lithium ion battery anodes from banana peels. ACS Nano 8(7), 7115-7129 (2014). https://doi.org/10.1021/nn502045y

27. S. Alvin, H.S. Cahyadi, J. Hwang, W. Chang, S.K. Kwak et al., Revealing the intercalation mechanisms of lithium, sodium, and potassium in hard carbon. Adv. Energy Mater. 10(20), 2000283 (2020). https://doi.org/10.1002/aenm.202000283

28. C. Bommier, T.W. Surta, M. Dolgos, X. Ji, New mechanistic insights on Na-ion storage in nongraphitizable carbon. Nano Lett. 15(9), 5888-5892 (2015). https://doi.org/10.1021/acs. nanolett.5b01969

29. Z. Li, L. Ma, T.W. Surta, C. Bommier, Z. Jian et al., High capacity of hard carbon anode in Na-ion batteries unlocked by pox doping. ACS Energy Lett. 1(2), 395-401 (2016). https:// doi.org/10.1021/acsenergylett.6b00172

30. Z. Li, C. Bommier, Z.S. Chong, Z. Jian, T.W. Surta et al., Mechanism of Na-ion storage in hard carbon anodes revealed by heteroatom doping. Adv. Energy Mater. 7(18), 1602894 (2017). https://doi.org/10.1002/aenm.201602894

31. B. Zhang, C.M. Ghimbeu, C. Laberty, C. Vix-Guterl, J.-M. Tarascon, Correlation between microstructure and Na storage behavior in hard carbon. Adv. Energy Mater. 6(1), 1501588 (2016). https://doi.org/10.1002/aenm.201501588

32. Q. Meng, Y. Lu, F. Ding, Q. Zhang, L. Chen et al., Tuning the closed pore structure of hard carbons with the highest $\mathrm{Na}$ storage capacity. ACS Energy Lett. 4(11), 2608-2612 (2019). https://doi.org/10.1021/acsenergylett.9b01900

33. Y. Li, Y. Lu, Q. Meng, A.C.S. Jensen, Q. Zhang et al., Regulating pore structure of hierarchical porous waste cork-derived hard carbon anode for enhanced Na storage performance. Adv. Energy Mater. 9(48), 1902852 (2019). https://doi.org/10.1002/ aenm.201902852

34. Y. Lu, C. Zhao, X. Qi, Y. Qi, H. Li et al., Pre-oxidationtuned microstructures of carbon anodes derived from pitch for enhancing Na storage performance. Adv. Energy Mater. 8(27), 1800108 (2018). https://doi.org/10.1002/aenm.20180 0108

35. C. Zhao, Q. Wang, Y. Lu, B. Li, L. Chen et al., High-temperature treatment induced carbon anode with ultrahigh $\mathrm{Na}$ storage capacity at low-voltage plateau. Sci. Bulletin 63(17), 1125-1129 (2018). https://doi.org/10.1016/j.scib.2018.07.018
36. Y. Li, Y.-S. Hu, H. Li, L. Chen, X. Huang, A superior lowcost amorphous carbon anode made from pitch and lignin for sodium-ion batteries. J. Mater. Chem. A 4(1), 96-104 (2016). https://doi.org/10.1039/C5TA08601A

37. Y. Li, L. Mu, Y.-S. Hu, H. Li, L. Chen et al., Pitch-derived amorphous carbon as high performance anode for sodium-ion batteries. Energy Storage Mater. 2, 139-145 (2016). https:// doi.org/10.1016/j.ensm.2015.10.003

38. J. Choi, M.E. Lee, S. Lee, H.-J. Jin, Y.S. Yun, Pyroproteinderived hard carbon fibers exhibiting exceptionally high plateau capacities for sodium ion batteries. ACS Appl. Energy Mater. 2(2), 1185-1191 (2019). https://doi.org/10.1021/ acsaem.8b01734

39. Z. Bi, Q. Kong, Y. Cao, G. Sun, F. Su et al., Biomass-derived porous carbon materials with different dimensions for supercapacitor electrodes: a review. J. Mater. Chem. A 7(27), 1602816045 (2019). https://doi.org/10.1039/C9TA04436A

40. J. Yang, S. Xiao, X. Cui, W. Dai, X. Lian et al., Inorganicanion-modulated synthesis of 2D nonlayered aluminum-based metal-organic frameworks as carbon precursor for capacitive sodium ion storage. Energy Storage Mater. 26, 391-399 (2020). https://doi.org/10.1016/j.ensm.2019.11.010

41. B. Yang, J. Chen, S. Lei, R. Guo, H. Li et al., Spontaneous growth of 3D framework carbon from sodium citrate for high energy- and power-density and long-life sodium-ion hybrid capacitors. Adv. Energy Mater. 8(10), 1702409 (2018). https:// doi.org/10.1002/aenm.201702409

42. Z. Ju, P. Li, G. Ma, Z. Xing, Q. Zhuang et al., Few layer nitrogen-doped graphene with highly reversible potassium storage. Energy Storage Mater. 11, 38-46 (2018). https://doi.org/10. 1016/j.ensm.2017.09.009

43. Z. Ju, S. Zhang, Z. Xing, Q. Zhuang, Y. Qiang et al., Direct synthesis of few-layer F-doped graphene foam and its lithium/ potassium storage properties. ACS Appl. Mater. Interfaces 8(32), 20682-20690 (2016). https://doi.org/10.1021/acsami. $6 \mathrm{~b} 04763$

44. Z. Hong, Y. Zhen, Y. Ruan, M. Kang, K. Zhou et al., Rational design and general synthesis of S-doped hard carbon with tunable doping sites toward excellent $\mathrm{Na}$-ion storage performance. Adv. Mater. 30(29), e1802035 (2018). https://doi.org/ 10.1002/adma.201802035

45. Y. Lu, J. Liang, Y. Hu, Y. Liu, K. Chen et al., Accurate control multiple active sites of carbonaceous anode for high performance sodium storage: insights into capacitive contribution mechanism. Adv. Energy Mater. 10(7), 1903312 (2020). https://doi.org/10.1002/aenm.201903312

46. C. Bommier, X. Ji, P.A. Greaney, Electrochemical properties and theoretical capacity for sodium storage in hard carbon: insights from first principles calculations. Chem. Mater. 31(3), 658-677 (2018). https://doi.org/10.1021/acs.chemmater.8b013 90

47. M.D. Levi, N. Levy, S. Sigalov, G. Salitra, D. Aurbach et al., Electrochemical quartz crystal microbalance (eqcm) studies of ions and solvents insertion into highly porous activated carbons. J. Am. Chem. Soc. 132(38), 13220-13222 (2010). https://doi.org/10.1021/ja104391g 
48. J.M. Griffin, A.C. Forse, W.Y. Tsai, P.L. Taberna, P. Simon et al., In situ NMR and electrochemical quartz crystal microbalance techniques reveal the structure of the electrical double layer in supercapacitors. Nat. Mater. 14(8), 812-819 (2015). https://doi.org/10.1038/nmat4318

49. S.-W. Zhang, W. Lv, C. Luo, C.-H. You, J. Zhang et al., Commercial carbon molecular sieves as a high performance anode for sodium-ion batteries. Energy Storage Mater. 3, 18-23 (2016). https://doi.org/10.1016/j.ensm.2015.12.004

50. A. Karatrantos, Q. Cai, Effects of pore size and surface charge on $\mathrm{Na}$ ion storage in carbon nanopores. Phys. Chem. Chem. Phys. 18(44), 30761-30769 (2016). https://doi.org/10.1039/ C6CP04611H

51. X. Zhang, S. Yang, X. Shan, S. Li, S. Tang, Insights into the effect of the interlayer spacings of bilayer graphene on the desolvation of $\mathrm{H}(+), \mathrm{Li}(+), \mathrm{Na}(+)$, and $\mathrm{K}(+)$ ions with water as a solvent: a first-principles study. Phys. Chem. Chem. Phys. 21(42), 23697-23704 (2019). https://doi.org/10.1039/C9CP0 2922B

52. J. Chmiola, C. Largeot, P.-L. Taberna, P. Simon, Y. Gogotsi, Desolvation of ions in sub-nanometer pores and its effect on capacitance and double-layer theory. Angew. Chem. Int. Ed. 120(18), 3440-3443 (2008). https://doi.org/10.1002/anie. 200704894

53. H. Zhang, G. Cao, Y. Yang, Z. Gu, Capacitive performance of an ultralong aligned carbon nanotube electrode in an ionic liquid at $60^{\circ} \mathrm{C}$. Carbon 46(1), 30-34 (2008). https://doi.org/ 10.1016/j.carbon.2007.10.023

54. H. Huang, S. Chen, X. Gao, W. Chen, A.T.S. Wee, Structural and electronic properties of PTCDA thin films on epitaxial graphene. ACS Nano 3(11), 3431-3436 (2009). https://doi. org/10.1021/nn9008615

55. K.J. Chen, D.G. Madden, T. Pham, K.A. Forrest, A. Kumar et al., Tuning pore size in square-lattice coordination networks for size-selective sieving of $\mathrm{CO}_{2}$. Angew. Chem. Int. Ed. 55(35), 10268-10272 (2016). https://doi.org/10.1002/anie. 201603934

56. N. Sun, Z. Guan, Y. Liu, Y. Cao, Q. Zhu et al., Extended "adsorption-insertion" model: a new insight into the sodium storage mechanism of hard carbons. Adv. Energy Mater. 9(32), 1901351 (2019). https://doi.org/10.1002/ aenm.201901351

57. Y. Liu, J.S. Xue, T. Zheng, J.R. Dahn, Mechanism of lithium insertion in hard carbons prepared by pyrolysis of epoxy resins. Carbon 34(2), 193-200 (1996). https://doi.org/10.1016/ 0008-6223(96)00177-7

58. Z. Jian, C. Bommier, L. Luo, Z. Li, W. Wang et al., Insights on the mechanism of Na-ion storage in soft carbon anode. Chem. Mater. 29(5), 2314-2320 (2017). https://doi.org/10.1021/acs. chemmater.6b05474

59. J. Yang, Z. Ju, Y. Jiang, Z. Xing, B. Xi et al., Enhanced capacity and rate capability of nitrogen/oxygen dual-doped hard carbon in capacitive potassium-ion storage. Adv. Mater. 30(4), 1700104 (2018). https://doi.org/10.1002/adma.201700104

60. K. Fang, D. Liu, X. Xiang, X. Zhu, H. Tang et al., Air-stable red phosphorus anode for potassium/sodium-ion batteries enabled through dual-protection design. Nano Energy 69, 104451 (2020). https://doi.org/10.1016/j.nanoen.2020.104451

61. C. Matei Ghimbeu, J. Górka, V. Simone, L. Simonin, S. Martinet et al., Insights on the $\mathrm{Na}+$ ion storage mechanism in hard carbon: discrimination between the porosity, surface functional groups and defects. Nano Energy 44, 327-335 (2018). https://doi.org/10.1016/j.nanoen.2017.12.013

62. W. Luo, C. Bommier, Z. Jian, X. Li, R. Carter et al., Low-surface-area hard carbon anode for $\mathrm{Na}$-ion batteries via graphene oxide as a dehydration agent. ACS Appl. Mater. Interfaces 7(4), 2626-2631 (2015). https://doi.org/10.1021/am507679x

63. B. Cao, Q. Zhang, H. Liu, B. Xu, S. Zhang et al., Graphitic carbon nanocage as a stable and high power anode for potassium-ion batteries. Adv. Energy Mater. 8(25), 1801149 (2018). https://doi.org/10.1002/aenm.201801149

64. C. Yang, F. Lv, K. Dong, F. Lai, K. Zhao et al., Metallic graphene-like $\mathrm{VSe}_{2}$ ultrathin nanosheets: superior potassium-ion storage and their working mechanism. Adv. Mater. 30(27), 1800036 (2018). https://doi.org/10.1002/adma.201800036

65. C. Yang, J. Feng, F. Lv, J. Zhou, C. Lin et al., Carbon-coated ultrathin metallic $\mathrm{V}_{5} \mathrm{Se}_{8}$ nanosheet for high-energy-density and robust potassium storage. Energy Storage Mater. 35, 1-11 (2021). https://doi.org/10.1016/j.ensm.2020.11.005

66. X. Yao, Y. Ke, W. Ren, X. Wang, F. Xiong et al., Defectrich soft carbon porous nanosheets for fast and high-capacity sodium-ion storage. Adv. Energy Mater. 9(6), 1803260 (2018). https://doi.org/10.1002/aenm.201803260

67. R. Alcántara, P. Lavela, G.F. Ortiz, J.L. Tirado, Carbon microspheres obtained from resorcinol-formaldehyde as high-capacity electrodes for sodium-ion batteries. Electrochem. SolidState Lett. 8(4), A222-A225 (2005). https://doi.org/10.1149/1. 1870612 